\title{
ESTILOS DE APRENDIZAGEM, DESEMPENHO ACADÊMICO E AVALIAÇÃO DOCENTE
}

\author{
LEARNING STYLES, ACADEMIC PERFORMANCE AND TEACHING \\ EVALUATION
}

\author{
SUZETE ANTONIETA LIZOTE \\ Universidade do Vale do Itajaí. Endereço: Av. Marcos Konder, 1.100, apto. \\ 801, Centro | 88301-302 | Itajaí/SC | Brasil. \\ (D)http://orcid.org/0000-0003-3575-1675 \\ lizote@univali.br \\ CLAUDIA SILVA RIBEIRO ALVES \\ Universidade do Vale do Itajaí. Endereço: Rua Camboriú, 689, apto. 04, \\ Centro | 88301-450| Itajaí/SC | Brasil. \\ Dhttp://orcid.org/0000-0001-5257-4389 \\ dinha.crsa@gmail.com
}

\section{SAYONARA DE FÁTIMA TESTON}

Universidade do Oeste de Santa Catarina. Endereço: Av. Nereu Ramos, 3777D | Seminário | 89813-000| Chapecó/SC | Brasil.

Dhttp://orcid.org/0000-0002-2469-1497

sayonara.teston@unoesc.edu.br

\section{JAQUELINE WERNER OLM}

Universidade do Vale do Itajaí. Endereço: Rua David Adão Schimidt, 168 | Barra do Rio | 88305-400 | Itajaí/SC | Brasil.

Dhttp://orcid.org/0000-0002-2689-2671

jaquelineolm@univali.br

\section{RESUMO}

O entendimento dos estilos de aprendizagem se torna necessário para identificar como os discentes se concentram, absorvem e transformam as informações recebidas em conhecimento. Este estudo tem como objetivo analisar a relação entre os estilos de aprendizagem com o desempenho acadêmico em estudantes de Ciências Contábeis e com a avalição sobre os docentes. O material para realizar o estudo descritivo e relacional com abordagem quantitativa foi obtido com questionários de autopreenchimento junto a 257 estudantes de todos os períodos do curso de Ciências Contábeis de uma universidade comunitária do Sul do Brasil. Os métodos estatísticos usados foram teste $\mathrm{t}$ de Student, análise de variância e análise de correlação. Os resultados mostraram a predominância do estilo auditivo $(37,4 \%)$, seguido do cinestésico $(23,7 \%)$ no modelo Vark, e do convergente (43,6\%), seguido do assimilador (40,1\%) no modelo de Kolb (1984), e os menos representados foram, respectivamente para esses dois modelos, o visual $(5,1 \%)$ e o divergente $(2,7 \%)$. Os estilos com menores desempenhos para o curso como um todo foi o 
divergente, que teve uma nota média dos alunos de 7,28 e o acomodador, com 7,47. A avaliação que os alunos fazem dos professores que ministram as disciplinas em que estão matriculados indica que os períodos com menores desempenhos avaliam melhor os docentes e vice-versa. Por fim, a autoavaliação que os professores fazem é estatisticamente maior que a feita pelos alunos em relação às práticas docentes, entretanto, as diferenças diminuem na medida em que se analisam os dados dos últimos períodos.

Palavras-chave: Curso de Ciências Contábeis. Kolb. Inventário de Vark.

\begin{abstract}
Understanding learning styles becomes necessary to identify how learners concentrate, absorb, and transform information they receive into knowledge. This study aims to analyze the relationship between learning styles and academic performance in students of Accounting Sciences with the evaluation of teachers. The material to perform the descriptive and relational study with a quantitative approach was obtained with self-completion questionnaires with 257 Accounting Sciences students from all periods at a Community University of Southern Brazil. The statistical methods used were Student's $t$ test, analysis of variance and correlation analysis. The results showed the predominance of the Auditory style (37.4\%), followed by Kinesthetic (23.7\%) in the Vark model and the Convergent (43.6\%) followed by the Assimilative (40.1\%) in the Kolb model (1984). The least represented were respectively the Visual (5.1\%) and the Divergent (2.7\%) style for these two models. The lowest performance styles were the Divergent, which had an average student grade of 7.28 and the Accommodative, with 7.47. Students' evaluation of teachers who teach the subjects in which these students are enrolled indicates that the years with lower performances evaluate teachers better and vice versa. Finally, the self-assessment that teachers made is statistically greater than the one made by the students about the teaching practices, however, the differences decrease as last year data are analyzed.
\end{abstract}

Keywords: Accounting Science course. Kolb. Vark's inventory.

\title{
1 INTRODUÇÃ̃O
}

$\mathrm{Na}$ atualidade, diante das mudanças ocasionadas pelo constante avanço da tecnologia e pela formação de blocos econômicos, o contador encontra-se em um novo ambiente, no qual aumentaram suas oportunidades, assim como as responsabilidades. Nesse sentido, para atender a essas novas exigências profissionais e sociais, o ensino da contabilidade procura constantemente se aprimorar. Para Vogt, Degenhart e Biavatti (2016, p. 64), "os profissionais dos cursos de Ciências Contábeis precisam sintetizar, analisar e avaliar o conhecimento de informações em um ambiente econômico e social".

É tarefa do ensino superior desenvolver as habilidades dos profissionais no sentido de torná-los críticos, articuladores, reflexivos e que sejam capazes de contextualizar, reunir e aplicar os conhecimentos discutidos. As críticas sobre os processos educacionais apontam o fato de estes estarem fundamentados sobre uma visão reducionista em desacerto com o ritmo das mudanças atuais (Bertero, 2006).

Convergente a isso, a avaliação dos processos de ensino e aprendizagem são importantes, porque conforme Dias Sobrinho (2010) ela é a principal ferramenta para implementar reformas educacionais, e tem relação com as transformações desejadas no presente e futuro.

Pode-se dizer que hoje se vive na sociedade da informação, e, de acordo com Lima (2003), faz-se necessário desenvolver em futuros profissionais de gestão a capacidade de dinamizar os processos gerenciais por meio de metodologias construtivistas, por relacionar a ação, reflexão e a colaboração do estudante no contexto da aprendizagem. Neste sentido, argumentam Andere e 
Araújo (2008, p. 92) que "estudar a educação e a qualidade de ensino contribui para a promoção de mudanças e para o progresso da sociedade". Desta forma, o entendimento dos estilos de aprendizagem se torna necessário para identificar como os discentes se concentram, absorvem e transformam as informações recebidas em conhecimento (Almeida, 2010).

Estilo de aprendizagem, segundo Miranda, Miranda e Mariano (2007), é o método que um indivíduo usa para adquirir conhecimento. Ele não é o que a pessoa aprende e sim o modo como ela se comporta durante o aprendizado. Complementam Santos, Colauto, Gassner, Antonovz e Correa (2014, p. 38) que "o estilo de aprendizagem combinado às metodologias e técnicas de ensino mais indicadas para cada caso podem facilitar tanto o aprendizado do estudante quanto o seu relacionamento com o professor e com o próprio curso".

Diversos autores investigaram os estilos de aprendizagem em estudantes de Ciências Contábeis e os achados relatam que posterior a sua verificação é possível adequar o processo de ensino-aprendizagem para torná-lo mais efetivo, ter um melhor aproveitamento e maior nível e qualidade (Silva, 2006; Oliveira, 2008; Oliveira Neto, Oliveira \& Miranda, 2009, Santos et al., 2014).

Com base no contexto descrito, este estudo buscou resposta a seguinte pergunta: Qual a relação entre o estilo de aprendizagem de estudantes do curso de Ciências Contábeis com o desempenho acadêmico e com a avaliação sobre os docentes? No intuito de dar resposta a esse questionamento, definiu-se como objetivo geral analisar a relação entre os estilos de aprendizagem com o desempenho acadêmico em estudantes de Ciências Contábeis e com a avalição sobre os docentes.

Com este estudo buscou-se obter novas evidências empíricas do tema analisado. A partir da identificação dos estilos de aprendizagem, é possível somar esforços entre os docentes e a instituição visando buscar mecanismos que facilitem o processo de ensino e aprendizagem, contribuindo, desta forma, para melhorar a conectividade e adaptabilidade entre docentes e discentes, tendo em vista que o desenvolvimento intelectual de um indivíduo é um dos principais objetivos da educação. Além disso, destaca-se que, conforme Cristofaro (2016), os estilos cognitivos são modificados em função de fatores biológicos, influências culturais e práticas educativas. Desta forma, acredita-se que por meio de alterações nas metodologias educacionais seja possível efetuar algumas mudanças nos estilos cognitivos dos estudantes, podendo, assim, lhes oferecer melhores oportunidades para inserção no mercado de trabalho.

Após esta introdução, o trabalho está estruturado em outras cinco seções. O marco teórico sobre o tema se apresenta na segunda seção e a abordagem metodológica na seguinte. Na sequência, analisam-se os dados, e na quinta seção apresentam-se as considerações finais. Por último, encontram-se as referências utilizadas.

\section{REFERENCIAL TEÓRICO}

Nesta seção apresenta-se o marco teórico definido como necessário à compreensão da abordagem adotada. Para tanto, discorreu-se sobre conceitos e modelos de estilos de aprendizagem, finalizando com estudos relacionados à temática.

\subsection{Estilos de aprendizagem}

Os estudos sobre ensino-aprendizagem apresentam-se constantemente não somente entre os educadores da área didático-pedagógica, mas também em todas as outras áreas do ensino, reforçando a necessidade de se investigar como ocorre esse processo no ensino da contabilidade (Mendes, 2000, Morozini, Cambrizzi \& Longo, 2007).

Os estilos de aprendizagem são de grande importância para um bom relacionamento entre docentes e discentes, principalmente para os primeiros, pois podem planejar sua didática segundo o melhor método de aprendizagem dos acadêmicos. O professor, independentemente de sua área 
de conhecimento, precisa ter em mente o planejamento de sua prática docente e o objetivo de aprendizagem para a escolha da melhor estratégia dentro do ambiente educacional (Masetto, 1994, Marion \& Marion, 2006). Neste sentido, McCarthy (2016) aponta que os estilos de aprendizagem têm sido foco de muitos estudos nos últimos 30 anos, em um esforço para melhorar o design institucional dos cursos e entender como os alunos aprendem.

Para Cerqueira (2000), a importância dos estilos de aprendizagem emergiu nos anos 1970 proveniente diretamente dos estudos sobre os estilos cognitivos, estando os seus criadores mais interessados numa orientação para a ação do que em aplicações mais práticas, nas áreas educacionais e de treinamento. Segundo Price (2004), eles normalmente são utilizados como uma metáfora para uma série de diferenças utilizadas pelos indivíduos no processo de aprendizagem.

Já para Gallert (2005), as teorias de estilos de aprendizagem são consideradas como resultado da hereditariedade (código genético), educação, personalidade e da adaptação do indivíduo às demandas do ambiente. Ainda para a autora, eles estão relacionados à forma particular de adquirir conhecimentos, habilidades ou atitudes por meio da experiência ou anos de estudo e seriam como um subconjunto dos estilos cognitivos. Neste sentido, Silva, Lima, Sonaglio e Godoi (2012) argumentam que à medida que o sujeito vai amadurecendo, os estilos de aprendizagem tendem a mudar com o tempo. Trata-se da intensidade de como cada indivíduo aprende de forma diferente das outras pessoas. "São modos especializados de adaptação, reforçados pela escolha permanente de situações em que um estilo é bem-sucedido" (Butzke \& Alberton, 2017, p. 73).

A criação de instrumentos que favoreçam o atendimento dos diversos estilos individuais também tende a favorecer a eficiência do ensino-aprendizagem. A partir do momento que o professor tem consciência das diferenças individuais dos alunos, poderá identificar grupos com características comuns e canais de percepção semelhantes (Marion \& Marion, 2006). Assim, será possível determinar estratégias de ensino adequadas aos perfis existentes nas turmas e, portanto, mais eficientes em seu meio profissional (Beck \& Rausch, 2015).

Os instrumentos para identificar os estilos de aprendizagem são, normalmente, baseados em dimensões para representar as diferentes formas de perceber e processar as informações e o modo de tomar decisões e organizar a própria vida, podendo fornecer boas estruturas para o planejamento do ensino. Neste sentido, Sonaglio, Lazzaretti e Pereira (2013) complementam que conhecer e identificar os diferentes estilos de aprendizagem dos discentes poderá contribuir para a escolha mais acertada das práticas metodológicas dos docentes.

Em 2011, Valaski, Malucelli e Reinehr publicaram uma pesquisa bibliométrica (2005 a 2011) sobre vários estudos empíricos internacionais, com o objetivo de identificar os estilos de aprendizagem no uso de metodologias ativas. No referido levantamento, constatou-se que o modelo de Felder e Silverman (1988) foi o mais usado, seguido pelos modelos de ciclo de aprendizagem vivencial de Kolb (1984) e Vark, elaborado por Fleming e Mills (1992). Portanto, nesta pesquisa, a identificação do estilo de aprendizagem será feita pelos modelos propostos por Kolb - LSI (1984) e Fleming e Mills (1992) com o inventário de Vark (Visual, Aural-Read, Write and Kinesthetic).

\subsection{Inventário de estilo de aprendizagem de Kolb}

$\mathrm{Na}$ teoria da aprendizagem experiencial (ELT), a aprendizagem humana e seu desenvolvimento possuem um papel central (Santos, Cirne \& Albuquerque, 2017). Esta teoria explica a importância das experiências anteriores dos alunos no processo de aprendizagem, esclarecendo que o discente deve experimentar situações, assumir riscos e dominar problemas vividos (Santos, Cirne \& Albuquerque, 2017).

Para Kolb (1984) existe a necessidade de identificar o perfil do aluno em relação aos aspectos dos estilos de aprendizagem que são individuais. É preciso refletir sobre o perfil de cada aprendiz para melhor explorar as práticas pedagógicas, bem como uma forma de avaliá-las. É possível perceber pelas descrições das características de cada estilo de aprendizagem que os alunos 
podem se diferenciar pela forma como agem, interpretam a realidade e pelas suas preferências para alcançar a aprendizagem.

Com base na ELT, Kolb (1984) apresentou os seguintes estilos de aprendizagem:

a) Divergente: tem a força oposta da aprendizagem da convergência, esta abordagem enfatiza a experiência concreta e observação reflexiva. O ponto positivo desta orientação reside na capacidade imaginativa e consciência de valores e significados para o indivíduo. Um indivíduo classificado neste estilo tem melhor desempenho em situações que exigem a geração de ideias alternativas, por exemplo por meio de brainstorming.

b) Assimilador: as capacidades de aprendizagem que predominam são a observação reflexiva e a conceituação abstrata. O ponto positivo desta orientação está presente no raciocínio indutivo e a capacidade de criar modelos teóricos, bem como assimilar observações discrepantes em uma explicação integrada. Este estilo é menos focado nas pessoas e mais preocupado com ideias e conceitos abstratos.

c) Convergente: baseia-se na aprendizagem de habilidades dominantes, conceituação abstrata e experimentação ativa. A maior vantagem deste estilo reside na resolução de problemas, tomada de decisão, e na aplicação prática de ideias. Neste estilo de aprendizagem, o conhecimento é organizado de tal forma que, por meio hipotético-dedutivo, pode ser focada em problemas específicos.

d) Acomodador: estilo contrário à assimilação, enfatiza a experiência concreta e a experimentação ativa. $\mathrm{O}$ intuito dessa orientação volta-se para fazer as coisas e se envolver em novas experiências por meio de planos e tarefas definidos. A ênfase adaptativa desta abordagem está na busca para correr riscos, ter oportunidades e ação. Este estilo é chamado acomodador por ser o estilo adequado para situações de adaptação em determinadas circunstâncias de forma imediata. Pessoas com estilos de aprendizagem acomodador são vistas à vontade com as pessoas, mas às vezes também são vistas como impacientes e agressivas.

\subsection{Inventário de estilo de aprendizagem de Vark}

O modelo de identificação de estilos de aprendizagem de Vark proposto por Fleming e Mills (1992) é focado nos canais sensoriais (visão, audição e cinestésico) preferidos pelas pessoas quando aprendem. Nesse modo são identificados quatro estilos de aprendizagem:

a) Visual (V): aprende melhor por meio de esquemas, figuras, gráficos e outros recursos visuais. Os recursos visuais são comuns no campo da administração, por apresentar figuras sobre ambientes organizacionais, esquemas como fluxogramas de processo ou organogramas da estrutura organizacional ou até gráficos que demonstram um histórico de vendas, crescimento, situações financeiras, pesquisas de mercado, entre outras informações (Fleming \& Mills, 1992).

b) Auditivo (A): prefere aprender na presença do professor, escuta as informações e explicações que são transmitidas por meio da fala. Com esse estilo, o aluno aprende melhor por sons, pode facilmente se distrair e desvia a atenção com outros sons que envolvem o ambiente de sala de aula. Aulas palestradas podem ser as preferidas por esse tipo de aluno (Fleming \& Mills, 1992).

c) Leitura e Escrita (R): alunos que possuem esse perfil possuem facilidades com a escrita. Desenvolvem melhor trabalhos que necessitem a busca por livros, se dão melhor com conceitos teóricos e preferem deixar formalizados seus conhecimentos no papel. Outra característica é que tendem a ser mais teóricos (Fleming \& Mills, 1992).

d) Cinestésico (K): prefere trabalhos em grupo. Esse aluno possui como principal característica a aprendizagem por meio de experiências. O aluno com esse perfil possui preferência por experiências sobre o objeto de estudo. Além disso, ao contrário do estilo Leitura e Escrita, possui pré-disposição pela colaboração entre os agentes envolvidos no processo de aprendizagem. Aulas práticas são preferidas por esse estilo (Fleming \& Mills, 1992). 
e) Multimodal (M): considerado híbrido e em um mesmo nível possui dois ou mais estilos do Modelo Vark. Esse estilo consegue se adequar melhor a diversas situações, já que sua adaptabilidade para métodos de ensino é fluida. (Fleming \& Mills, 1992).

Sobre o modelo Vark, é interessante comentar que não existe clara definição se o modelo de estilos proposto foi delineado a estudantes em idade de formação escolar ou adultos. O modelo trata dos estilos de aprendizagem independente da faixa etária do aluno.

\subsection{Estudos relacionados}

Vários estudos utilizaram os modelos de estilos de aprendizagem para identificar determinadas características os acadêmicos. Cerqueira (2000) aplicou no Brasil o inventário de Kolb (1984), identificando a relação de alunos de diversos cursos de graduação com os estilos de aprendizagem mais presentes. $\mathrm{O}$ estudo evidenciou que o estilo assimilador, predominante nos universitários pesquisados, mantém-se estável em todos os semestres e áreas. Também sugere que no Sul do Brasil seja realizado estudo com instituições privadas, já que só participaram de sua amostra instituições públicas.

O estudo de Kolb e Kolb (2010) retrata a importância da aprendizagem experiencial, porém não estereotipa alunos, parte do estudo com seus respectivos estilos de aprendizagem. O estudo é uma forma de demonstrar a importância da aprendizagem experiencial, e que o jogo proporciona maior responsabilidade ao aluno quanto à gestão de sua autoaprendizagem. Outro benefício está no aluno não se concentrar apenas no placar, já que este só possui sentido ao considerar sua experiência na forma de jogar.

Assim como o estudo de Cerqueira (2000) identificou certa relação do estilo de aprendizagem e a área de formação, Cordeiro e Silva (2012) corroboram ao identificar que a maioria dos alunos pesquisados em Administração também possuem estilo de aprendizagem "assimilador". Ao relacionar estilos de aprendizagem com desempenho curricular em finanças dos cursos de Administração, não encontraram relação significativa, mas, identificaram relação entre a experiência profissional e o estilo de aprendizagem, convergente com os pressupostos de Kolb (1984), cujo foco reside na Aprendizagem Experiencial.

Miranda, Miranda e Mariano (2007) utilizaram o Modelo Vark de Fleming e Mills (1992) apenas em cursos de Ciências Contábeis. Os autores apontam uma grande concentração de alunos e professores cinestésicos, e que as técnicas tradicionais de aulas expositivas, resolução de exercícios e seminários ainda são as predominantes em sala de aula, mesmo não sendo algumas destas vistas pelos alunos como as melhores práticas pedagógicas

Nos estudos realizados por Madkur, Mrtvi e Lopes (2008) os estilos de aprendizagem foram analisados para determinar a formação de equipes no processo de aprendizagem com o uso de jogos de empresa. Os resultados apontaram que o comportamento das equipes no processo de análise e tomada de decisão não apresentou diferenças significativas entre os estilos. Reis e Paton (2009), por sua vez, estudaram as diferenças de estilos de discentes de Ciências Contábeis entre instituições públicas e privadas. Os resultados mostraram maior predominância do estilo convergente, independentemente do tipo de instituição.

Na pesquisa de Sonaglio, Lazzaretti e Pereira (2013) foram comparados os estilos de aprendizagem dos discentes de Administração e Tecnologia em Gestão. Os resultados evidenciaram que os estilos em ambos os cursos são semelhantes, tendo predominado o estilo assimilador. Bacinello e Domingues (2016) pesquisaram os estilos de aprendizagem dos alunos de Ciências Contábeis e Administração com o intuito de verificar se o perfil dos acadêmicos exerce influência nesses estilos. Concluíram que em ambos os cursos o estilo preponderante foi o assimilador, seguido do convergente em Contábeis e do acomodador em Administração.

Lima Filho, Bezerra e Silva (2016) buscaram identificar o estilo de aprendizagem predominante dos alunos do curso de graduação em Ciências Contábeis nas modalidades presenciais e à distância em instituições públicas e privadas do estado da Bahia. Os resultados 
apontaram o estilo assimilador como preponderante. Os estudos de Santos, Cirne e Albuquerque (2017) também evidenciaram a predominância do estilo assimilador em alunos dos cursos de Administração, Ciências Contábeis e Serviço Social em instituições de ensino superior do Alto Sertão paraibano. Butzke e Alberton (2017) investigaram a relação entre os estilos de aprendizagem de discentes de Administração com o uso de jogos de empresa. Os achados da pesquisa mostraram que os estilos de aprendizagem apresentaram diferença significativa na estratégia de ensino nas dimensões de processamento e entrada. Simões, Melo e Batista (2018) investigaram a relação entre os estilos de aprendizagem dos discentes e os métodos de ensino utilizados por docentes do curso de Ciências Contábeis da Universidade Federal de Campina Grande. Os resultados mostraram que entre os alunos, o estilo predominante foi o assimilador e, entre os professores, foi o convergente. Com base nos estudos levantados, observa-se que os estilos cognitivos têm sido investigados nas diversas áreas do conhecimento e a área de Contabilidade também tem sido objeto de estudo.

\section{MATERIAL E MÉTODO DE PESQUISA}

Considerando o objetivo proposto, esta pesquisa pode ser considerada como descritiva. Para Vergara (1998), os objetivos da pesquisa descritiva se referem à obtenção de informações sobre um fenômeno ou sobre determinada população e à descrição de suas características. Do ponto de vista da abordagem do problema, classifica-se como quantitativa. A avaliação quantitativa compreende organizar, sumarizar, caracterizar e interpretar os dados numéricos (Martins \& Theóphilo, 2007). No que tange aos procedimentos técnicos, foi do tipo levantamento, que tem como objetivo contribuir para o conhecimento de uma área particular de interesse por meio da coleta de dados sobre indivíduos ou sobre o ambiente destes (Trez \& Matos, 2006).

A pesquisa foi realizada em uma Universidade Comunitária do Sul do Brasil com discentes do curso de Ciências Contábeis. O número total de alunos que responderam foi de 257, representando mais de $50 \%$ dos estudantes matriculados que no momento da coleta dos dados eram 462, sendo,55 do primeiro período, 24 do segundo, 47 do terceiro, 17 do quarto, 39 do quinto, 18 do sexto, 33 do sétimo e 24 do oitavo período. Os dados foram coletados em sala de aula e em horários previamente agendados com o docente responsável pela disciplina. Durante a pesquisa, um dos pesquisadores permaneceu em sala de aula para esclarecer quaisquer dúvidas. Para cada um dos estudantes se registrou o estilo de aprendizagem segundo os dois modelos empregados e ainda a sua nota média no curso.

Os dados sobre a avaliação dos professores do curso de Ciências Contábeis foram obtidos junto à comissão permanente de avaliação da Universidade. Em cada semestre letivo realiza-se a avaliação institucional e geram-se os boletins de desempenho pontuando 10 itens, a partir dos quais se origina a nota média. A avaliação é feita tanto pelo discente que está matriculado na disciplina avaliada quanto pelo próprio docente que ministra essa matéria, existindo assim, dois valores a serem considerados.

Para tanto, se disponibilizaram dois instrumentos de pesquisa aos alunos de todos os períodos do curso, sendo eles o derivado do modelo de Fleming e Mills (1992), conhecido como inventário Vark, e o decorrente do modelo de aprendizagem experiencial de Kolb (1984). Ambos os questionários já foram validados no Brasil, o Vark, por Miranda, Miranda e Mariano (2011) e o de Kolb, por Cerqueira (2000). A versão traduzida ao português de ambos os questionários está disponibilizada na tese de Dalfovo (2013).

Para identificar o estilo de aprendizagem do aluno conforme o modelo Vark (2012), utilizou-se um instrumento composto de 16 questões. Cada pergunta possui quatro opções de resposta em que o aluno precisa se posicionar sobre a forma como aprende melhor. Ao final desse questionário, existe um gabarito no qual são identificados os estilos, sendo: visual (V), auditivo (A), leitura e escrita (R) e cinestésico (K). A soma destes representará o perfil predominante sobre 
a forma como o aluno prefere aprender, porém, quando há empate entre as pontuações de dois ou mais estilos, se considera um quinto estilo denominado multimodal (M).

Por sua vez, o inventário referido ao modelo de Kolb tem 12 questões e também quatro categorias, sendo que o respondente deve ordenar desde a maneira que menos apreende (1) até melhor para apreender (4). A atribuição a um dos quatro estilos do modelo, acomodador (Ac), assimilador (As), convergente $(\mathrm{Cv})$ ou divergente (Dv), é feita a partir da pontuação de cada dimensão da aprendizagem experiencial. Ou seja, as dimensões experiência concreta, observação reflexiva, conceituação abstrata e experimentação ativa. Com base nisso se gera um gráfico radar e segundo o triângulo que tiver maior superfície se assigna o estilo (Cerqueira, 2000). Quando os triângulos tiveram superfícies muito semelhantes entre si, neste trabalho, se adaptou um quinto estilo que se chamou multimodal $(\mathrm{Mu})$.

Este estudo não foi submetido ao Comitê de Ética em Pesquisa (CEP), pois implica em risco mínimo para os sujeitos participantes. De acordo com Shaughnessy, Zechmeister e Zechmeister (2007, p. 66), "[...] um risco mínimo significa que o dano ou inconformidade que os participantes podem experimentar em uma investigação não é maior que o que podem experimentar em suas vidas diárias ou durante provas físicas ou psicológicas de rotina". Ainda, para os autores, somente em situações onde a possibilidade de dano físico ou psicológico é significativamente maior do que ocorre rotineiramente na vida cotidiana, é necessário submeter a pesquisa ao CEP.

Todos os dados levantados foram organizados numa planilha eletrônica Excel, onde foram feitos os pré-processamentos necessários antes das análises estatísticas (Hair Jr., Black, Anderson \& Tatham, 2009). A seguir, as bases de dados por período foram importadas ao software Statistica com o qual foram feitas as comparações de médias usando o teste $\mathrm{t}$ e a análise de variância (Anova). Os preditores categóricos usados nas Anovas foram os períodos e os estilos de aprendizagem. Por fim, a relação entre as notas médias por períodos e a avaliação que os discentes fazem dos docentes foi aferida pelo coeficiente de correlação e aquela avaliação foi comparada com a autoavaliação dos professores pelo teste $t$ de Student.

\section{RESULTADOS}

Ao processar os dados do primeiro período com os estilos segundo o modelo Vark, constatou-se que existiam dois outliers, um para o estilo multimodal $(9,34)$ e outro para o visual $(8,62)$, que foram excluídos antes de desenvolver a Anova. A comparação simultânea não foi significativa ( $\mathrm{p}=0,1617)$, contudo os alunos cujo estilo é de leitura e escrita possuem a maior nota média $(8,13)$ e os visuais, a menor $(7,35)$. Se for considerada a diferença mínima significativa de Fisher como teste de comparação a posteriori, os estudantes que possuem o estilo leitura e escrita têm média maior do que os visuais e os auditivos $(7,53)$.

Ao considerar os estilos segundo o modelo de Kolb (1984), também se constatou a presença de dois outliers, um para os acomodadores $(6,63)$ e outro para os convergentes $(9,34)$. Por outra parte, só houve um aluno com estilo de aprendizagem divergente, cuja média era de 6,91 . A comparação simultânea dos quatro estilos não mostrou diferenças significantes, mas ao comparálos com o valor único do divergente se constata que todas as médias foram estatisticamente maiores, como se exibe na Tabela 1 .

Tabela 1

Teste de médias contra uma constante de referência

\begin{tabular}{c|c|c|c|c|c|c|c|c}
\hline Estilos & Média & d.p. & $\mathbf{N}$ & Erro padrão & Divergente & Valor-t & g.1 & p \\
\hline Acomodador & 7,818 & 0,7226 & 5 & 0,3232 & 6,91 & 2,8097 & 4 & 0,048 \\
\hline Assimilador & 7,668 & 0,6801 & 26 & 0,1334 & 6,91 & 5,6809 & 25 & 0,000 \\
\hline Convergente & 7,720 & 0,6394 & 16 & 0,1598 & 6,91 & 5,0667 & 15 & 0,000 \\
\hline Multimodal & 7,838 & 0,6704 & 7 & 0,2534 & 6,91 & 3,6613 & 6 & 0,011 \\
\hline
\end{tabular}


A análise descritiva dos dados do segundo período, conforme o inventário Vark, mostrou que não houve alunos com o estilo visual, e, ainda, a existência de um outlier dentre os multimodais $(8,84)$. Após sua retirada, e usando os quatro estilos como preditores na Anova, constatou-se que não há diferenças na comparação simultânea $(\mathrm{p}=0,2126)$. Entretanto, a maior média voltou a ser aquela dos que possuem estilo leitura e escrita $(7,74)$.

Conforme o modelo de Kolb (1984), os estilos se distribuem do seguinte modo: um aluno acomodador, 10 assimiladores, 12 convergentes e um multimodal. Não verificou-se a existência de estudante com estilo divergente. Feita a análise de outliers, o valor 8,84 apareceu como tal entre os convergentes. Inicialmente, fez-se o contraste de médias entre os convergentes e os assimiladores, o que resultou em igualdade, e a seguir se compararam aquelas médias com a média do multimodal $(7,43)$ e do acomodador $(7,00)$. No primeiro caso não se verificaram diferenças, mas no segundo os assimiladores tiveram uma média estatisticamente maior, com $5 \%$ de significância, e os convergentes, com 10\%, como mostra-se na Tabela 2.

Tabela 2

Teste de médias contra uma constante de referência

\begin{tabular}{c|c|c|c|c|c|c|c|c}
\hline Estilos & Média & d.p. & N & Erro padrão & Acomodador & Valor-t & g.1 & p \\
\hline Assimilador & 7,63 & 0,5563 & 10 & 0,1759 & 7,00 & 3,5838 & 9 & 0,006 \\
\hline Convergente & 7,35 & 0,5710 & 12 & 0,1648 & 7,00 & 2,1247 & 11 & 0,057 \\
\hline
\end{tabular}

A avaliação dos outliers do terceiro período permitiu identificar quatro entre os alunos com estilo leitura e escrita e, por sua parte, constatou-se que somente dois estudantes possuem estilo visual. $\mathrm{Na}$ Anova realizada com os estilos auditivo, cinestésico, leitura e escrita, e multimodal, a comparação simultânea não mostrou diferenças significativas. No entanto, ao comparar aqueles quatro estilos com o valor médio dos dois alunos visuais, verifica-se que os auditivos e os multimodais têm médias significativamente menores que os visuais, com $10 \%$ de significância, e isso também ocorre com os cinestésicos, como se apresenta na Tabela 3.

Quando se consideraram os estilos segundo o modelo de Kolb (1984), observou-se apenas um outlier entre os assimiladores $(9,44)$, assim como só há dois alunos entre os divergentes e não há representantes dos multimodais. Na comparação simultânea não se confirmaram diferenças como quando comparados os acomodadores, assimiladores e convergentes com o valor único da média dos dois divergentes.

\section{Tabela 3}

\section{Teste de médias contra uma constante de referência}

\begin{tabular}{c|c|c|c|c|c|c|c|c}
\hline Estilos & Média & d.p. & N & Erro padrão & Visual & Valor-t & g.1 & p \\
\hline Auditivo & 7,73 & 0,6347 & 17 & 0,1539 & 8,13 & $-2,5951$ & 16 & 0,020 \\
\hline Cinestésico & 7,55 & 0,7194 & 8 & 0,2543 & 8,13 & $-2,2656$ & 7 & 0,058 \\
\hline Leit/Escrita & 7,99 & 0,1794 & 5 & 0,0802 & 8,13 & $-1,6952$ & 4 & 0,165 \\
\hline Multimodal & 7,50 & 0,5353 & 11 & 0,1614 & 8,13 & $-3,9035$ & 10 & 0,003 \\
\hline
\end{tabular}

O quarto período foi aquele em que menos estudantes responderam os questionários, mas estiveram representados todos os estilos do inventário Vark, embora só se classificasse um pelo estilo leitura e escrita e também um como visual. Não foram registrados outliers, e ao fazer a Anova, as médias dos outros três estilos foram iguais. Nas comparações das médias dos auditivos, dos cinestésicos e multimodais com os valores fixos, do aluno que tem estilo leitura e escrita $(7,42)$, e do que tem estilo visual $(7,75)$ só se constata que os auditivos $(8,18)$ têm uma média estatisticamente maior que aqueles valores.

Os alunos do quarto período, pelos estilos da aprendizagem experiencial de Kolb (1984), se classificaram em dois acomodadores, nove assimiladores e seis convergentes. Isto é, não houve representante dos divergentes nem dos multimodais. A comparação das médias entre os assimiladores e os convergentes não mostra diferenças, e quando essas médias se comparam com 
o valor fixo 7,21, que corresponde à média dos dois acomodadores, ambos os estilos têm médias maiores, como se exibe na Tabela 4.

Tabela 4

Teste de médias contra uma constante de referência

\begin{tabular}{c|c|c|c|c|c|c|c|c}
\hline Estilos & Média & d.p. & N & Erro padrão & Acomodador & Valor-t & g.1 & p \\
\hline Assimilador & 8,03 & 0,5632 & 9 & 0,1877 & 7,21 & 4,3977 & 8 & 0,002 \\
\hline Convergente & 7,81 & 0,2848 & 6 & 0,1163 & 7,21 & 5,2170 & 5 & 0,003 \\
\hline
\end{tabular}

A análise dos dados levantados no quinto período pelo inventário Vark permitiu identificar que entre os alunos com estilo multimodal houve dois outliers. Por sua parte, não houve representantes do estilo leitura e escrita e somente um visual. A comparação simultânea das médias pela Anova confirma sua igualdade e quando elas se comparam com o valor do aluno de estilo visual verifica-se que elas foram estatisticamente menores, como se pode apreciar na Tabela 5.

Tabela 5

Teste de médias contra uma constante de referência

\begin{tabular}{c|c|c|c|c|c|c|c|c}
\hline Estilos & Média & d.p. & N & Erro padrão & Visual & Valor-t & g.1 & p \\
\hline Auditivo & 7,50 & 0,6770 & 22 & 0,1443 & 8,30 & $-5,510$ & 21 & 0,000 \\
\hline Cinestésico & 7,34 & 0,5663 & 9 & 0,1888 & 8,30 & $-5,0604$ & 8 & 0,001 \\
\hline Multimodal & 7,73 & 0,2135 & 5 & 0,0955 & 8,30 & $-6,0203$ & 4 & 0,004 \\
\hline
\end{tabular}

Na análise dos dados levantados dos estilos segundo o modelo de Kolb (1984), mostrouse a presença de só um outlier entre os assimiladores e, por sua vez, houve apenas um aluno com estilo multimodal. A Anova realizada resultou na igualdade das médias dos quatro estilos incluídos na comparação simultânea, e quando aquelas médias se compararam com o valor fixo do estilo multimodal $(7,18)$, constatou-se que só os convergentes $(7,77)$ tiveram uma média estatisticamente maior $(\mathrm{p}=0,002)$.

No sexto período também foram poucos os estudantes que responderam a survey, mas todos os estilos do Vark estiveram representados. Houve só um aluno com estilo multimodal, dois com estilo visual e outros dois com leitura e escrita. Do estilo auditivo foram sete alunos e do cinestésico seis, completando os 18 respondentes desse período. Não verificaram-se outliers, e a comparação de médias não mostrou diferenças significativas. Quando comparadas as médias dos diversos estilos com o valor fixo do único aluno multimodal pode-se observar que unicamente a média dos auditivos $(7,51)$ é significativamente menor $(\mathrm{p}=0,016)$ do que a nota do multimodal $(8,16)$.

Com os dados do modelo de Kolb (1984) a maioria dos alunos (10) se classifica como convergente, seguido dos assimiladores (4) e dos acomodadores (3). Completa o número de respondentes um aluno multimodal. Isto é, não se registrou nenhum aluno como divergente. Nas comparações simultâneas constatou-se a igualdade de médias, sendo o que também se verificou ao comparar as médias com a nota $(8,16)$, o valor fixo do estudante multimodal.

Para o sétimo período a análise descritiva dos dados do inventário Vark permitiu detectar um outlier no estilo leitura e escrita e, embora todos os estilos estivessem representados, do visual só houve um único estudante. Nas comparações simultâneas, assim como quando comparadas às médias com a nota $(7,70)$ do aluno de estilo visual, não se observou diferenças significativas entre os valores.

No caso dos estilos segundo a aprendizagem experiencial de Kolb (1984) não se registraram alunos com estilos acomodador e divergente. A análise descritiva confirmou a presença de quatro outliers, sendo dois do estilo assimilador e outros dois do convergente. A Anova realizada com os três estilos confirmou a igualdade de suas médias.

Com os dados levantados para o oitavo e último período segundo o modelo Vark, verificouse que todos os estilos estiveram representados, entretanto só houve um aluno que teve o estilo visual. Feito o pré-tratamento dos dados, não se detectaram outliers e a comparação simultânea 
das médias dos outros quatro estilos confirmou sua igualdade. Obteve-se o mesmo resultado, com $5 \%$ de significância, ao comparar aquelas médias com a nota do estudante com estilo visual $(7,53)$, mas com $10 \%$ a média dos alunos com estilo leitura e escrita $(7,35)$ resulta ser estatisticamente menor.

Finalmente, os dados colhidos com o questionário do modelo de Kolb (1984), ao serem avaliados quanto à presença de outliers, mostraram que existia um entre os assimiladores. Do estilo divergente não houve representante, e do acomodador apenas um aluno, cuja nota média no curso era 7,71. Feita a Anova entre os estilos assimilador, convergente e multimodal houve diferenças significativas $[\mathrm{F}(2,19)=7,283 ; \mathrm{p}=0,005]$, com a média dos estudantes de estilo multimodal $(8,45)$ maior do que os assimiladores $(7,51)$ e os convergentes $(7,48)$. Ao comparar as médias desses três estilos com a nota do discente visual confirma-se que com $5 \%$ de significância existe igualdade, mas com $10 \%$ ela é igual apenas com os multimodais e maior do que os outros dois estilos.

Depois de analisar os dados de cada período, considerando os dois modelos de estilos de aprendizagem, procedeu-se a realização de uma Anova para comparar as médias dos oito períodos tomados em conjunto e em cada um dos estilos de ambos os modelos (Tabela 6).

Tabela 6

Comparação simultânea das médias de todos os períodos juntos

\begin{tabular}{c|c|c|c|c|c|c|c|c|c|c|c}
\hline Estilo & $\mathbf{T}$ & $\mathbf{A}$ & $\mathbf{C}$ & $\mathbf{L E}$ & $\mathbf{V}$ & $\mathbf{M}$ & $\mathbf{A c}$ & $\mathbf{A s}$ & $\mathbf{C v}$ & Dv & $\mathbf{M u}$ \\
\hline $\mathbf{T}$ & $\mathbf{( 7 , 6 5 )}$ & igual & igual & igual & igual & igual & igual & igual & igual & menor & igual \\
\hline $\mathbf{A}$ & 0,679 & $\mathbf{( 7 , 6 0 )}$ & igual & igual & igual & igual & igual & igual & igual & igual & igual \\
\hline $\mathbf{C}$ & 0,625 & 0,940 & $\mathbf{( 7 , 5 9 )}$ & igual & igual & igual & igual & igual & igual & igual & igual \\
\hline $\mathbf{L E}$ & 0,248 & 0,122 & 0,106 & $\mathbf{( 7 , 8 2 )}$ & igual & igual & menor & igual & igual & menor & igual \\
\hline $\mathbf{V}$ & 0,336 & 0,175 & 0,154 & 0,849 & $\mathbf{( 7 , 7 6 )}$ & igual & menor & igual & igual & menor & igual \\
\hline $\mathbf{M}$ & 0,426 & 0,228 & 0,201 & 0,697 & 0,847 & $\mathbf{( 7 , 7 9 )}$ & menor & igual & igual & menor & igual \\
\hline $\mathbf{A c}$ & 0,179 & 0,343 & 0,381 & 0,017 & 0,028 & 0,037 & $\mathbf{( 7 , 4 7 )}$ & igual & igual & igual & maior \\
\hline $\mathbf{A s}$ & 0,814 & 0,517 & 0,470 & 0,352 & 0,462 & 0,574 & 0,118 & $\mathbf{( 7 , 6 9 )}$ & igual & menor & igual \\
\hline $\mathbf{C v}$ & 0,958 & 0,718 & 0,663 & 0,228 & 0,312 & 0,396 & 0,196 & 0,773 & $\mathbf{( 7 , 6 5 )}$ & menor & igual \\
\hline $\mathbf{D v}$ & 0,046 & 0,089 & 0,099 & 0,005 & 0,008 & 0,011 & 0,331 & 0,031 & 0,050 & $\mathbf{( 7 , 2 8 )}$ & maior \\
\hline $\mathbf{u m}$ & 0,388 & 0,214 & 0,190 & 0,811 & 0,955 & 0,899 & 0,039 & 0,518 & 0,362 & 0,011 & $\mathbf{( 7 , 7 8 )}$ \\
\hline
\end{tabular}

Nota. Na diagonal principal os valores entre parênteses correspondem às médias.

T (Total); A (Auditivos); C (Cinestésicos); Le (Leitura e Escrita); V (Visuais); M (Multimodais); Ac (Acomodadores); As (Assimiladores); Cv (Convergentes); Dv (Divergentes); Mu (Multimodais).

Como se pode observar na Tabela 6, a média calculada para os alunos que possuem o estilo divergente (Dv), segundo o modelo de Kolb (1984), foi estatisticamente menor, com 5\% de significância, que a média de todos os estilos tomados em conjunto $(\mathrm{T}=$ total $)$ e que as médias dos que usam leitura e escrita (LE), os visuais (V) e os multimodais (M). Ainda, com 10\% de significância, também foi menor do que auditivos (A) e os cinestésicos (C). Ou seja, praticamente de todos os estilos do modelo Vark.

Por sua vez, ao considerar os outros estilos do modelo de Kolb (1984) se verifica que os divergentes têm média menor do que os multimodais (Mu), os assimiladores (As) e os convergentes $(\mathrm{Cv})$. Há apenas um valor igual à média dos acomodadores (Ac). Estes, os acomodadores, foram os que tiveram a segunda menor média, que resultou estatisticamente menor do que os multimodais $(\mathrm{Mu})$ da aprendizagem experiencial e do que as médias dos que usam leitura e escrita (LE), os visuais (V) e os multimodais (M) do modelo Vark.

Devido ao número de respondentes do sexo feminino (171), o qual foi quase o dobro dos respondentes masculinos (86), testaram-se as diferenças entre proporções. No caso dos estilos no modelo Vark não se constatou nenhuma diferença, porém no caso do modelo de Kolb (1984) apenas a proporção de alunas de estilo assimilador foi estatisticamente maior, com uma significância de $10 \%$, que a proporção de estudantes homens $(\mathrm{p}=0,068)$. Por outra parte, considerando o modelo de Kolb (1984), as alunas com estilo assimilador somadas (63) às com estilo convergente (74) constituem uma proporção de 0,80117 , enquanto para os homens de estilo 
assimilador (40) somados aos do estilo convergente (38) chegam à proporção de 0,906977, constatando-se diferença significativa $(\mathrm{p}=0,0157)$. Isto significa que os alunos de sexo masculino com esses estilos, proporcionalmente, são maioria e, tomados em conjunto, deve-se considerar que mais de $83 \%$ dos alunos possuem esses estilos.

Considerando o modelo Vark as predominâncias são invertidas em relação ao assinalado no estudo de Miranda et al. (2007), pois na amostra por eles trabalhada os cinestésicos foram 49\% e os auditivos, 24\%. Entretanto, os menos representados foram os alunos de estilo visual. Quanto ao modelo de Kolb (1984), na amostra analisada por Paton, Oliveira e Azevedo (2004), assinalase o estilo acomodador como o mais presente, o que não ocorreu nos dados levantados para esta pesquisa. Porém, coincidindo com aqueles autores, confirmou-se que alunos de estilo divergente foram também os menos representados.

Quando se analisa o relacionamento entre as notas médias dos alunos com as avaliações que eles fazem das disciplinas nas quais estão matriculados se constata que possuem um coeficiente de correlação negativo e com 10\% de significância $(r=-0,6455 ; p=0,084)$. Conforme se expõe na Figura 1, os alunos que tiveram em conjunto médias menores avaliaram com notas maiores os docentes e vice-versa.

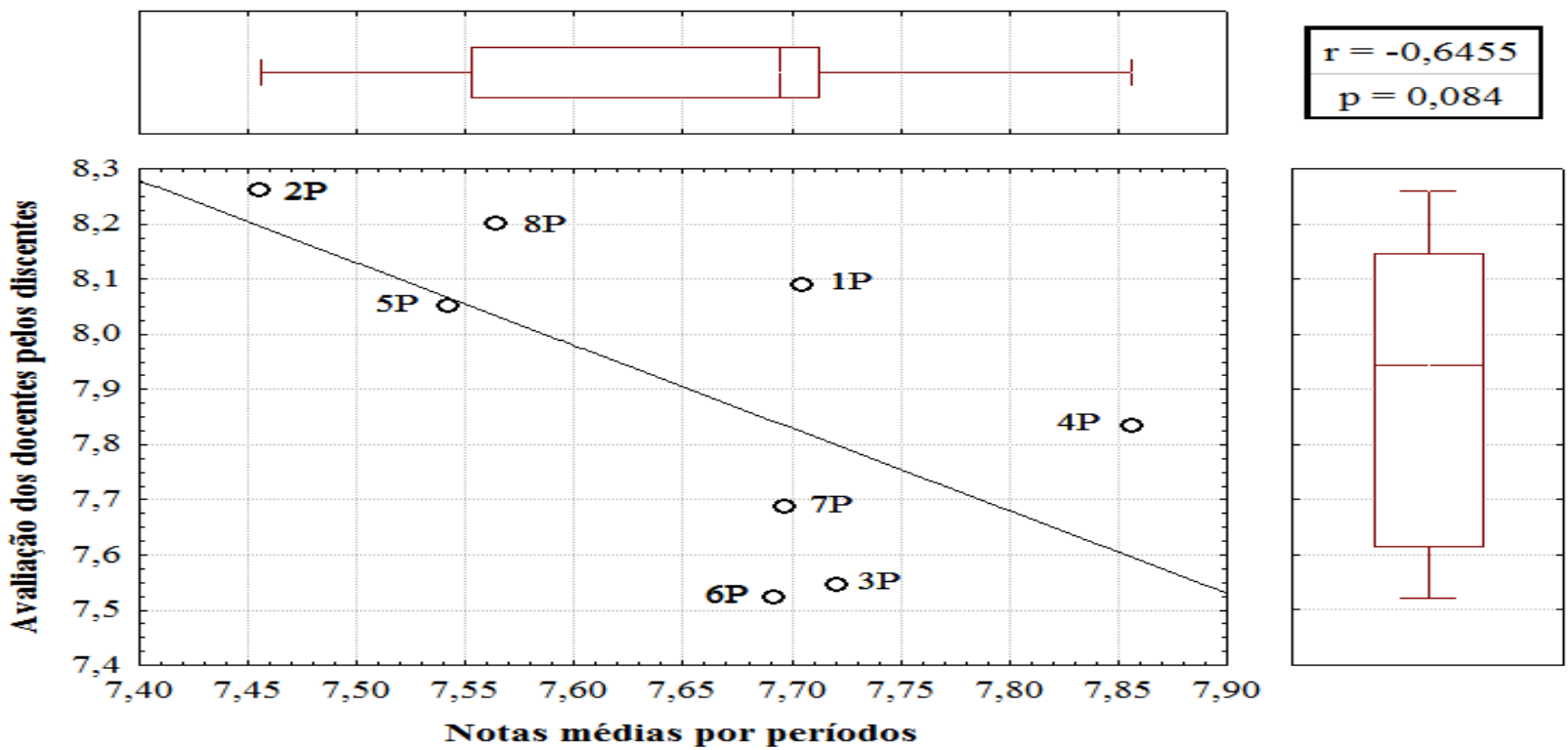

Figura 1. Relação entre as notas médias dos alunos e a avaliação que eles fazem dos docentes

Por fim, compararam-se as médias das notas com que os discentes avaliam os docentes das disciplinas em que estão matriculados com as notas da autoavaliação docente. Para tanto, utilizouse o teste $t$ para distribuições independentes. $O$ resultado demostra que os docentes se atribuem notas maiores, que resultam numa média de 9,05, estatisticamente maior $(\mathrm{p}=0,000)$ que aquela calculada a partir das avaliações dos alunos $(7,90)$. Essa diferença pode estar associada à satisfação dos alunos com seu aprendizado. No primeiro ano, considerando os dois semestres, é de 2,3 pontos; no segundo ano essa diferença sobe para 3,9; no terceiro cai para 1,9; e para o último ano atinge apenas 1,1. Isto indica que os discentes, na medida em que progridem no curso e aumentam seus conhecimentos, avaliam com melhor precisão o ensino, aproximando sua pontuação com a autoavaliação que os professores fazem.

O curso onde os dados foram levantados possui características particulares que se manifestam na avaliação docente pelo discente. Como assinalado em Kraemer, Lizote e Verdinelli (2015), os professores com menores cargas horárias foram os melhor avaliados, e isto pode-se vincular com o fato de eles exercerem a profissão contábil em escritórios e trazerem para sala de aula temáticas atuais e do próprio âmbito profissional. Desse modo, a dificuldade para o 
aprendizado assinalada por Morozini et at. (2007), que a maioria dos alunos preferem que sejam abordados assuntos que lhes despertem maior atenção, é minorada no caso desses professores.

\section{CONSIDERAÇÕES FINAIS}

Este estudo teve como objetivo analisar a relação entre os estilos de aprendizagem com o desempenho acadêmico em estudantes de Ciências Contábeis e com a avalição sobre os docentes. Os resultados mostraram que todos os estilos de aprendizagem de ambos os modelos considerados nesta pesquisa, o de Fleming e Mills (1992) e o de Kolb (1984), ocorrem entre os estudantes do curso de Ciências Contábeis investigado. Contudo, na amostra obtida, no modelo Vark predominam os auditivos (37,4\%), seguidos dos cinestésicos (23,7\%), e no de Kolb (1984) os convergentes $(43,6 \%)$, seguidos dos assimiladores $(40,1 \%)$. Os estilos menos representados foram, respectivamente para aqueles modelos, os visuais $(5,1 \%)$ e os divergentes $(2,7 \%)$.

Como todos os estilos foram observados entre os estudantes do curso, e levando em conta o salientado por Oliveira et al. (2011) e Miranda et al. (2007), ressalta-se que as técnicas de ensino nem sempre são as mais apropriadas aos estilos de aprendizagem dos discentes, e torna-se importante que os professores estejam cientes dessa diversidade de estilos presente nas turmas e da necessidade de adequar seu labor docente para contribuir na apropriabilidade do conhecimento pelos estudantes. Entretanto, deve-se levar em conta que na amostra considerada, 83,7\% dos estudantes possuem estilos convergente e assimilador, segundo o modelo de Kolb, com maior incidência nos alunos do sexo masculino.

Em vista dos resultados obtidos, conclui-se que o uso dos modelos de Fleming e Mills (1992) e de Kolb (1984) possibilitaram identificar os estilos de aprendizagem de todos os 257 alunos que participaram da amostra levantada, compreendendo todos os períodos do curso. O uso da nota média de cada aluno possibilitou avaliar as semelhanças e diferenças entre os alunos, considerando seus estilos de aprendizagem como preditores e da análise global de todos os períodos, e constatou-se que os estudantes com estilo divergente foram os que tiveram o pior desempenho, seguidos pelos de estilo acomodador.

Quanto à avaliação do desempenho docente feito pelos discentes pode-se verificar que as avaliações com pontuações maiores foram feitas pelas turmas que tiveram menores notas médias, e vice-versa. O qual permite concluir que essa relação negativa avaliza a qualidade do sistema de avaliação docente pelo discente. Por sua vez, as diferenças entre as pontuações dadas pelos alunos e a autoavaliação se minimizam na medida em que se consideram os períodos mais adiantados, encontrando-se a maior semelhança no último ano do curso.

Sugere-se que próximas pesquisas busquem identificar o estilo de aprendizagem de discentes de outros cursos da área de gestão. Com tal esforço, acredita-se que seja possível para os docentes conhecerem melhor seus alunos, e, assim, possam oferecer serviços educacionais com qualidade e que satisfaçam suas expectativas, contribuindo também para a eficácia do processo de ensino-aprendizagem.

\section{REFERÊNCIAS}

Almeida, K. R. (2010). Descrição e análise de diferentes estilos de aprendizagem. Revista Interlocução, 3(3), 38-49.

Andere, M. A., \& Araújo, A. M. P. (2008). Aspectos da formação do professor de ensino superior de Ciências Contábeis: uma análise dos programas de pós-graduação. Revista Contabilidade e Finanças, 19(48), 91-102. 
Bacinello, E., \& Domingues, M. J. C. S. (2016). Estilos de aprendizagem: um estudo comparativo entre os cursos de contabilidade e administração em uma IES. Anais do Congresso USP de Controladoria e Contabilidade, São Paulo, SP, Brasil, 16.

Beck, F., \& Rausch, R. B. (2015). Fatores que influenciam o processo de ensino-aprendizagem na percepção de discentes do curso de Ciências Contábeis. Revista Contabilidade Vista \& Revista, 25(2), 38-58.

Bertero, C. O. (2006). Ensino e pesquisa em Administração. São Paulo: Thomson Learning.

Cerqueira, T. C. S. (2000). Estilos de aprendizagem em universitários. Campinas, 2000. Tese de Doutorado em Educação, Pós-Graduação em Educação, Universidade Estadual de Campinas, Campinas, SP, Brasil.

Butzke, M. A., \& Alberton, A. (2017). Estilos de aprendizagem e jogos de empresa: a Percepção discente sobre estratégia de ensino e ambiente de aprendizagem. REGE - Revista de Gestão, $24,72-84$.

Cordeiro, R. A., \& Silva, A. B. da. (2012). Os estilos de aprendizagem influenciam o desempenho acadêmico dos alunos de finanças? Rev. Adm. UFSM, 5(2), 243-261.

Cristofaro, M. (2016). Cognitive styles in dynamic decision making: a laboratory experiment. International Journal of Management and Decision Making. 15(1), 53-82.

Dalfovo, M. S. (2013). Casos multiformatos em administração: análise da influência dos estilos e ambientes de aprendizagem. Biguaçu. Tese de Doutorado em Administração e Turismo, Universidade do Vale do Itajaí, Biguaçu, SC, Brasil.

Dias Sobrinho, J. (2010). Avaliação e transformações da educação superior brasileira (1995-2009): do Provão ao SINAES. Avaliação: Revista da Avaliação da Educação Superior, 15(1), 195 224.

Felder, R. M., \& Silverman, L. K. (1988). Learning and teaching styles in engineering education. Engineering Education, 78(7), 674-681.

Fleming, N. D., \& Mills, C. (1992). Not another inventory, rather and catalyst for reflection. To Improve the Academy, 11, 137.

Gallert, C. S. (2005). Sistema hipermídia para ensino baseado nos estilos de aprendizagem. Santa Maria. Dissertação de Mestrado em Ciências da Computação, Universidade Federal de Santa Maria, Santa Maria, RS, Braisl.

Hair Jr., J. F., Black, W. C., Babin, B. J., Anderson, R. E., \& Tatham R. L. (2009). Análise multivariada de dados (6a ed.). Porto Alegre: Bookman.

Kolb, A. Y., \& Kolb, D. A. (2010). Learning to play, playing to learn: a case study of a ludic learning space. Journal of Organizational Change Management, 23(1), 26-50.

Kolb, D. A. (1984). Experimental learning: experience as the source of learning and development. New Jersey: Prentice-Hall, Englewood Cliffs. 
Kraemer, M. E. P., Lizote, S. A., \& Verdinelli, M. A. (2016). Desempenho docente no curso de ciências contábeis: uma avaliação integradora com variáveis pessoais. Anais do Congresso Internacional de Gestão Universitária, Mar del Plata, Argentina, 10.

Lima, M. C. (2003). Estudos de casos hipertextuais: rumo a uma inovação no Método Harvard de ensino de gestão. $R A C, 7(3), 77-99$.

Lima Filho, N., Bezerra, E. S., \& Silva, T. B.S. (2016). Estilo de aprendizagem dos alunos do curso de Ciências Contábeis. Revista Gestão Universitária na América Latina-GUAL, 9(2), 95-112.

Madkur, F. N., Mrtvi, V. O., \& Lopes, P. C. (2008). Estilos de aprendizagem e constituição de equipes: um estudo no contexto dos jogos de empresas. Anais do Encontro Nacional dos Programas de Pós-Graduação e Pesquisa em Administração, Rio de Janeiro, RJ, Brasil, 22.

McCarthy, M. (2016). Experiential learning theory: From theory to practice. Journal of Business \& Economics Research (Online), 14(3), 91-131.

Marion, J. C., \& Marion, A. L. C. (2006). Metodologias de ensino na área de negócios: para cursos de administração, gestão, contabilidade e MBA. São Paulo: Atlas.

Martins, G. A., \& Theóphilo, C. R. (2007). Metodologia da investigação científica para ciências sociais aplicadas. São Paulo: Atlas.

Masetto, M. (1994). Didática: a aula como centro. São Paulo: Moderna.

Mendes, J. B. (2000). Utilização de jogos de empresas no ensino de contabilidade: uma experiência no curso de Ciências Contábeis da Universidade Federal de Uberlândia. Contabilidade Vista \& Revista, 11(3), 23-41.

Miranda, C. de S., Miranda, R. Á. De M., \& Mariano, A. S. (2007). Estilos de aprendizagem e sua inter-relação com as técnicas de ensino: uma avaliação com o modelo Vark no curso de ciências contábeis de uma IES no interior paulista. Anais do Congresso da Associação Nacional dos Programas de Pós-Graduação em Ciências Contábeis, Gramado/RS, Brasil.

Morozini, J. F., Cambruzzi, D., \& Longo, L. (2007). Fatores que influenciam o fator ensino aprendizagem no curso de ciências contábeis do ponto de vista acadêmico. Revista Capital Científico, 5(1), 88-102.

Oliveira Neto, J. D. de, Oliveira, V. de, \& Miranda, C. de S. (2009). Estilos cognitivos: uma pesquisa com estudantes de contabilidade. Brazilian Busniness Review, 6(1), 82-103.

Oliveira, V. de. (2008). Os estilos cognitivos e o ensino de contabilidade: um estudo na faculdade UNIRG/TO. Dissertação de Mestrado em Controladoria e Contabilidade. Universidade de São Paulo, Ribeirão Preto, SP, Brasil.

Paton, I. C., Oliveira, C. R., \& Azevedo, R. E. A. (2004). Os estilos de aprendizagem dos alunos de graduação em Ciências Contábeis da Universidade de Londrina-UEL: uma aplicação. Anais do Congresso USP de Contabilidade, São Paulo, SP, Brasil. 
Price, L (2004). Individual differences in learning: cognitive control, cognitive style, and learning style. Educational Psycology, 24(5), 2004.

Reis, L. G. dos, \& Paton, C. (2009). Estilos de aprendizagem: uma análise dos alunos do curso de ciências contábeis pelo método KOLB. Anais do Encontro Nacional dos Programas de PósGraduação e Pesquisa em Administração, São Paulo, SP, Brasil, 23.

Santos, D. F., Colauto, R., Gassner, F. P., Antonovz, T., \& Correa, M. D. (2014). Estilos de aprendizagem: estudo com estudantes de Ciências Contábeis de uma universidade pública. Revista Contabilidade UFBA, 8(1), 35-53.

Santos, E. L. L., Cirne, G. M. P., \& Albuquerque, L. S. (2017). Estilos de aprendizagem à luz dos postulados de KOLB: uma análise das práticas nos cursos de administração, ciências contábeis e serviço social em instituições de ensino superior do alto sertão paraibano. Revista de Pesquisa Interdisciplinar, 2(2), 384-399.

Shaughnessy, J. J., Zechmeister, E. B., \& Zechmeister, J. (2007). Métodos de investigación en Psicología (7a ed.). México: McGraw-Hill Interamericana.

Silva, A. B. da, Lima, T. B. de, Sonaglio, A. L. B., \& Godoi, C. K. (2012). Dimensões de um sistema de aprendizagem em ação para o ensino de administração. Administração, Ensino $e$ Pesquisa RAEP, 13(1), 9-41.

Silva, D. M. da. (2006). O impacto dos estilos de aprendizagem no ensino de contabilidade na FEA/RP-USP. Dissertação de Mestrado em Controladoria e Contabilidade, Universidade de São Paulo, Ribeirão Preto, SP, Brasil.

Simões, M. P. de A., Mello, L. S. A. de, \& Batista, F. F. (2018). Análise relacional entre estilos de aprendizagem e métodos de ensino em um curso de Ciências Contábeis. Revista Evidenciação Contábil \& Finanças, 6(1), 75-95.

Sonaglio, A. L. B., Lazzaretti, K., \& Pereira I. (2013). Estilos de aprendizagem: um estudo comparativo entre discentes do curso de Administração e dos cursos de Tecnologia em Gestão. RACE, Ed. Especial Anpad, 45-80.

Trez, G., \& Matos, C. A. de. (2006). A influência da ordem das questões nos resultados de pesquisas surveys. Anais Encontro Nacional dos Programas de Pós-Graduação e Pesquisa em Administração, Salvador, BA, Brasil, 20.

Valaski, A., \& Brozik D. (2006). Learnning styles and online education. Campu- Wide Information Systems, 23(5), 325-335.

Vergara, S. C. (1998). Projetos e relatórios de pesquisa em Administração. São Paulo: Atlas.

Vogt, M., Degenhart, L., \& Biavatti, V. T. (2016). Relação entre formação docente, metodologias de ensino e resultados do Exame Nacional de Desempenho dos Estudantes de Ciências Contábeis. Revista Catarinense da Ciência Contábil, 15(45), 63-77. 